PROCEEDINGS OF THE

AMERICAN MATHEMATICAL SOCIETY

Volume 27, Number 1, January 1971

\title{
FIXED POINTS FOR CONTRACTIVE MULTIFUNCTIONS
}

\author{
R. E. SMITHSON
}

ABstract. Let $F: X \rightarrow X$ be a point closed multifunction on the bounded metric space $(X, d)$. Let $d$ denote the Hausdorff metric for the nonempty closed subsets of $X$. Then $F$ is contractive iff $d(F(x), F(y))<d(x, y)$ for all $x, y \in X$. We give conditions under which contractive multifunctions have fixed points.

1. Introduction. The fixed point theorem for contraction maps on a complete metric space into itself is well known, and a number of generalizations of this result have appeared [1], [2], [3]. Further, Nadler [5] has proved an extension of the fixed point theorem for contraction maps to multivalued functions. The purpose of the present paper is to extend a fixed point theorem of Edelstein's [2] for contractive mappings to multivalued functions. In the proof of the main theorem, we make use of Edelstein's methods.

In the following $X$ will denote a bounded metric space with metric $d$, and we shall let $d$ denote the Hausdorff metric on the space $S(X)$ of nonempty closed subsets of $X$. A multifunction $F: X \rightarrow X$ is a point to set correspondence (i.e. a multivalued function), and we use upper case $F, G$, etc. to denote a multifunction. Further, the multifunction is called poini closed (compact) in case $F(x)$ is a closed (compact) set for all $x \in X$. If $A \subset X$, then $F(A)=\bigcup\{F(x): x \in A\}$ and $F^{-1}(A)$ $=\{x: F(x) \cap A \neq \varnothing\}$. We shall use the following definitions.

Definition. The multifunction $F$ is upper semicontinuous (U.S.C.) iff for each closed set $A \subset X$, the set $F^{-1}(A)$ is closed.

One of our major tools will be the concept of an orbit of the multifunction $F$ at the point $x$.

Definition. An orbit $\mathcal{O}(x)$ of the multifunction $F$ at the point $x$ is a sequence $\left\{x_{n}: x_{n} \in F\left(x_{n-1}\right)\right\}$ where $x_{0}=x$. We shall use $\theta(x)$ as a sequence and as a set as the situation demands.

2. The main theorem. Before stating the main theorem of this paper, we need some more definitions and preliminary results.

Definition. The multifunction $F$ is contractive iff for each $x_{1}, x_{2} \in X$ with $x_{1} \neq x_{2}, \hat{d}\left(F\left(x_{1}\right), F\left(x_{2}\right)\right)<d\left(x_{1}, x_{2}\right)$.

Presented to the Society, January 23, 1970 under the title $A$ note on $M$-isometries and contractive multifunctions; received by the editors January 20, 1970.

AMS 1969 subject classifications. Primary 5465, 5485.

Key words and phrases. Contractive multivalued functions, fixed point theorems, orbits for multifunctions, regular orbits, cluster points of orbits.

Copyright (c) 1971, American Mathematical Society 
An immediate consequence of the definition is: If $y_{1} \in F\left(x_{1}\right)$, then there is an element $y_{2} \in F\left(x_{2}\right)$ such that $d\left(y_{1}, y_{2}\right)<d\left(x_{1}, x_{2}\right)$.

Definition. An orbit $O(x)$ is called a regular orbit iff

$$
d\left(x_{n+1}, x_{n+2}\right) \leqq d\left(x_{n}, x_{n+1}\right) \text { and } d\left(x_{n+1}, x_{n+2}\right) \leqq d\left(F\left(x_{n}\right), F\left(x_{n+1}\right)\right) \text {. }
$$

REMARKs. (1) Let $F$ be a point compact, contractive multifunction. Define an orbit $\mathcal{O}(x)$ by choosing $x_{n} \in F\left(x_{n-1}\right)$ so that

$$
d\left(x_{n-1}, x_{n}\right)=d\left(x_{n-1}, F\left(x_{n-1}\right)\right)=\inf \left\{d\left(x_{n-1}, y\right): y \in F\left(x_{n-1}\right)\right\} .
$$

Then, since $F$ is contractive, it follows that $\theta(x)$ is regular.

(2) It is fairly easy to construct simple examples to show that a contractive multifunction need not be U.S.C. However, if $F$ is point compact and contractive, then one can show that $F$ is U.S.C.

Furthermore, if $F$ is a point compact U.S.C. multifunction, if $x_{n} \rightarrow x_{0}$, and if $y_{n} \in F\left(x_{n}\right)$ for each $n$, then one can show that there is a subsequence $\left\{y_{n_{i}}: i \geqq 1\right\}$ which converges to a point in $F\left(x_{0}\right)$. Similarly one can show that if $F$ is point closed and contractive, if $x_{n} \rightarrow x_{0}$ and if $y_{n} \rightarrow y_{0}$ with $y_{n} \in F\left(x_{n}\right)$, then $y_{0} \in F\left(x_{0}\right)$.

We are now ready to state our main theorem.

TheOREM 1. Let $F$ be a point closed, contractive multifunction. If there is a regular orbit $\mathcal{O}(x)$ for $F$ which contains a convergent subsequence $x_{n_{i}} \rightarrow y_{0}$ such that $x_{n_{i}+1} \rightarrow y_{1}$, then $y_{1}=y_{0}$ (i.e. $F$ has a fixed point).

Proof. Let $\mathcal{O}(x)$ be a regular orbit with $x_{n_{i}} \rightarrow y_{0}, x_{n_{i}+1} \rightarrow y_{1}$ and $y_{1} \in F\left(y_{0}\right)$. We define a function $f: Y=X \times X \backslash \Delta \rightarrow R$ where $\Delta$ is the diagonal as follows and $R$ is the reals:

$$
r(p, q)=d(F(p), F(q)) / d(p, q) .
$$

Then $r$ is a continuous function and since $F$ is contractive, $r(p, q)$ $<1$. Thus if $y_{1} \neq y_{0}$ there is an $a, 0<a<1$, and an open set $U$ of $Y$ such that $\left(y_{0}, y_{1}\right) \in U$ and if $(p, q) \in U$, then $0 \leqq r(p, q)<a$. Now choose $\rho>0$ so that (i) $\rho<\frac{1}{3} d\left(y_{0}, y_{1}\right)$ and (ii) if $B_{1}=B\left(y_{0}, \rho\right), B_{2}$ $=B\left(y_{1}, \rho\right)$ then $B_{1} \times B_{2} \subset U$.

Since $x_{n_{i}} \rightarrow y_{0}$ and $x_{n_{i}+1} \rightarrow y_{1}$, there is an $N$ such that $i \geqq N$ implies that $x_{n_{i}} \in B_{1}$ and $x_{n_{i}+1} \in B_{2}$. Therefore $d\left(x_{n_{i}}, x_{n_{i}+1}\right)>\rho$ for all $i>N$.

On the other hand from the definition of $r$ and the choice of $U$

$$
d\left(F\left(x_{n_{i}}\right), F\left(x_{n_{i}+1}\right)\right)<a d\left(x_{n_{i}}, x_{n_{i}+1}\right),
$$

and since $\theta(x)$ is regular, we get $d\left(x_{n_{i}+1}, x_{n_{i}+2}\right)<a d\left(x_{n_{i}}, x_{n_{i}+1}\right)$. Further, if $l>j>N$, 


$$
d\left(x_{n_{l}}, x_{n_{l+1}}\right) \leqq d\left(x_{n_{l-1}+1}, x_{n_{l-1}+2}\right)<a d\left(x_{n_{l-1}}, x_{n_{l-1}+1}\right) .
$$

Then by repeating this argument we get: $d\left(x_{n_{l}}, x_{n_{l}+1}\right)<a^{l-j} d\left(x_{n_{j}}, x_{n_{j+1}}\right)$. But with fixed $j, a^{l-j \rightarrow 0}$ as $l \rightarrow \infty$, which implies that $d\left(x_{n_{l}}, x_{n_{l}+1}\right) \rightarrow 0$ as $l \rightarrow \infty$. This contradicts $d\left(x_{n_{l}}, x_{n_{l}+1}\right)>\rho$ for $l>N$. Thus we conclude that $y_{0}=y_{1}$ and hence, $F$ has a fixed point.

We can deduce a theorem of Fraser and Nadler [4] from Theorem 1. For this let $F$ be a multifunction and define $\hat{F}$ by $\hat{F}(A)$ $=\bigcup\{F(x): x \in A\}$ for $A \subset X$. If $F$ is point compact and contractive, then $\hat{F}$ is a continuous function on the compact subsets of $X$ into the compact subsets of $X$. Then we get

CoROllaRY 1.1. Let $F$ be a point compact, contractive multifunction on $X$. If there is a compact subset $A$ of $X$ such that some subsequence of the sequence $\left\{\hat{F}^{n}(A): n \geqq 1\right\}$ of iterates of $\hat{F}$ at $A$ converges to a compact set, then $\hat{F}$ has a fixed point.

Finally, another corollary is:

CoRollary 1.2. If $F$ is a point closed, contractive multifunction on the compact, metric space $X$ into itself, then $F$ has a fixed point.

\section{REFERENCES}

1. L. P. Belluce and W. A. Kirk, Fixed-point theorems for certain classes of nonexpansive mappings, Proc. Amer. Math. Soc. 20 (1969), 141-146. MR 38 \#1663.

2. M. Edelstein, On fixed and periodic points under contractive mappings, J. London Math. Soc. 37 (1962), 74-79. MR 24 \#A2936.

3. —_, On nonexpansive mappings, Proc. Amer. Math. Soc. 15 (1964), 689695. MR $29 \# 2780$.

4. R. B. Fraser, Jr. and S. B. Nadler, Jr., Sequences of contractive maps and fixed points, Pacific J. Math. 31 (1969), 659-667. 488.

5. S. Nadler, Multivalued contraction mappings, Pacific J. Math. 30 (1969), 475-

UNIVERSITY OF WYoming, LARAMIE, Wyoming 82070 